Participative Leadership and Its Relationship with Organizational Identification among Specialists in Youth Welfare Departments, Helwan University

Asst. Prof. Dr. Abeer Fathi Mohammed Shaltout*

Management leadership in its essence means the ability to effect on others and to motivate them to achieve goals of the establishment and its priorities, to seek constantly for developing it and to upgrade its performance and outputs. It is assured that administrative processes do not change or is not developed by itself and so, we should focus on staff as they are considered as the foundation and drive of the growth and development.

Participative leadership encourage all subordinates to take part in all matters effectively by providing them with information, strengthening them with tasks, involving them in open discussions and having them to make decision. It endeavors to motivate subordinates, to take care of their feeling and to guide them. It is characterized by cooperation and participation.

In contrast, the organizational identification is considered one of the topics that has received a great importance by researchers in the field of management as it affects performance, behavior of individuals, productivity of establishments and regularity of their performance.

Organizational identification has an importance pouring at the end in the interest of the organization to achieve its goals efficiently and effectively and in the individual's interest himself as it develops in the individual the spirit of affiliation, loyalty and sincerity and thus, it grow up creativity, innovation and cooperation.

In the light of the above, the objective of the current research was to identify the participative leadership and its relationship with organizational identificationin specialists in youth welfare departments, Helwan University and the descriptive method was used as it suits the nature of the research. The research sample included (75) specialists in departments of youth welfare departments, Helwan University. As a tool of collecting data, the researcher used two questionnaire forms viz. participative leadership in directors of departments of youth welfare, Helwan University and organizational identification in specialists in departments of youth welfare, Helwan University designed by the researcher.

The results concluded that the score of practicing the participative leadership was high and the level of organizational identification in specialists had a high score and there was a significant direct correlation between participative leadership and organizational identification and finally the authority delegation dimension as one of the participative leadership dimensions got a contribution ratio in determining the level of organizational identification in specialists in youth welfare departments, Helwan University according to opinions of the research sample.

\footnotetext{
*Dept. of Sports Management and Recreation, Faculty of Physical Education for Girls, Helwan University, A.R. E.
} 
Introduction and research problem:

Management leadership in its essence means the ability to effect on others, to motivate them to achieve goals of the establishment and its priorities and to seek constantly for developing it and to upgrade its performance and outputs. It is assured that the administrative processes do not change or is developed by itself and hence, we should focus on the staff as they are considered as the foundation and drive of growth and development (Hafez, Al-Moghaidi and Al-Behairi, 2013).

Contemporary developments and variables have imposed necessity of existence of a strong, participative, cooperative and flexible management able to meet challenges establishments face successfully. Also they imposed the need for the existence of a type of individuals having experience, wisdom and ability to act on others.

Participative leadership is one of the recent topics in management that its interest began at the end of nineties in the last century as the recognition of the importance of the relationship between participative leadership and its effect on staff is still limited impacting the ability of departments and their preparedness to enable their members to carry out tasks they have been requested to do and to seek for achieving the establishment's progress (Abo Al-Kheir, 2013).

Ayed Mustafa (2016) indicated that participative leadership could encourage all subordinates to take part in all matters by notifying them with information, to evaluate them with tasks and to involve them in open discussions as well as taking decision. It seeks for motivating subordinates, taking care of their feeling and directing them. It is characterized by cooperation and participation.

That was assured by Abo Aitah (2013) that the participative type would be the best and the most successful one among leadership types as it depends on dialogue, participation, exchanging opinions, respecting subordinates' personality and equalizing between achieving their wishes and their objectives together with achieving goals of the establishment.

The researcher has shown that the importance of participative leadership lies in the fact that the organization works as a team, however, their specializations are different in respect of participation in making decision, planning to achieve joint objectives and connectivity within the organization. It strengthens human relationships among staff and makes them feel the leadership and their belonging to the organization.

Also the study of Al-Qurashi (2013) emphasized that the participative leadership could be considered as the highest effective type in respect of its impact on staff and performance quality. It might contribute to problems facing the organization.

In contrast, organizational identification is considered as a topic that is received a great attention by researchers in the field of leadership as it affects individuals' 
performance and behavior, productivity and performance regularity of establishments.

The organizational identification has importance pouring at the end into the organization's interest to achieve its goals efficiently and effectively and into the individual's interest himself as it develops the spirit of belonging, loyalty and sincerity in the individual and consequently, it develops creativity, innovation and cooperation (Al-Shawawrah, 2016).

Khloud Al-Zughbi (2013) illustrated that when the worker had a high position in the establishment that would lead to form his organizational identity, to make the best effort in the job, to have a strong wish to achieve the highest level of this position and so reflecting positively to his performance and productivity.

The researcher concluded that the leadership style would be the method by which the leader could achieve his goals leaving effects on an organization and staff working in it. The leader might approve one of the styles that might reflect on the method of work of the organization and the way the staff treated each other.

The study of Al-Shamri (2012) indicated that the role of the leader would be emerged when he contributed to the occurrence of the organizational identification process through his role to find out a state where the individual's objectives would be identical to those of the organization.

Also the study of Al-Ghamdi (2014) showed that participative leadership played a very important role in the educational and learning field as it recommended that it could be necessary to practice participative leadership in that field as it had a great effect on developing and upgrading the educational and learning systems and activities.

The sense of importance of human element has grown in the work as considered the most important in organizations but the concept of participative leadership and connecting it with organizational identification in an important and wide sector like departments of youth welfare, Helwan University on the basis that such sector represents one of the service sectors taking care of university students of different hobbies and satisfying their wishes through different activities outside the framework of academic study has not discussed by scientific studies to the knowledge of the researcher and therefore, the current investigation has been prepared to make benefits from this field.

The research problem is that the number of specialists working in departments of youth welfare, Helwan University represented by committees of different student activities due to different reasons including a broad sector of specialists have reached the age of pension and new specialists have not recruited to complete the work system in different committees of youth welfare leading to requesting any specialist of youth welfare to work in more than one committees to achieve tasks and plans placed and 
different student activities together with the committee he has assigned to work for it. This performance may be because the specialists give attention to achieve goals outlined in departments of youth welfare in the university for their loyalty and belonging to youth welfare to have the work system to get succeeded. To tackle this situation in the shadow of the existence of not enough numbers of specialists to deal with this situation but it could be because it is necessary to have a conscious leadership represented by directors of departments for youth welfare in the university and the leadership type they follow. Through this understanding the current research idea has been emerged in an attempt to identify the participative leadership and its relationship with organizational identification in specialists in departments of youth welfare, Helwan University.

Research importance:

It is clear in the following points:

1- The importance of departments of youth welfare as considered as a center of radiation from and to students for everything new in activities and competitions.

2- Focusing on two modern variables and those are participative leadership and organizational identity.

3- Research variables represent an important role in building continuing the role of departments of youth welfare, Helwan University.

Research objective:

The aim of the current investigation was to know participative leadership and its relationship with organizational identification in sports specialists in departments of youth welfare, Helwan University through outlining the following:

1- The score of practicing participative leadership among directors of departments of youth welfare, Helwan University from specialists' point of view.

2- The level of organizational identification among specialists in departments of youth welfare, Helwan University.

3- The relationship between participative leadership and organizational identification among specialists in departments of youth welfare, Helwan University.

4- Rate of contribution of dimensions of participative leadership in outlining the level of organizational identification among specialists in departments of youth welfare, Helwan University.

Research questions:

1- What is the score of practicing participative leadership among directors of departments of youth welfare, Helwan University from specialists' point of view? 
2- What is the level of organizational identification among specialists in departments of youth welfare, Helwan University?

3- Is there a significant correlation between participative leadership and organizational identification among specialists in departments of youth welfare, Helwan University?

4- What is the ratio of contribution of dimensions of participative leadership in outlining the level of organizational identification among specialists in departments of youth welfare, Helwan University?

Terminology:

Participative leadership:

Homoud and Al-Sheikh (2010) identified it as the subordinates would take part in making and taking decisions related to the work and the leader would depend on delegating some of his authorities to employees working with him in a manner commensurate with their responsibilities and decentralization of leadership, availability of an active communications, motivating subordinates and investing their creative and innovative abilities.

Also Abdel Aziz Al Askar (2016) defined it as a leading style emphasizing on actual participation of staff in all sides of the management process, granting them more powers and supporting their confidence that could reflect to the increase of their productivity and their feeling of belonging.

The researcher means in the current investigation that participative leadership is that director of youth welfare reacts with specialists in team situations such as participating in making decision, delegating power, human relationships, efficiency of communication and availability of information to achieve goals outlined.

Organizational identification:

Al-Ghazali and Al-Khuzaie (2016) identified it as a progressive and continuous state began to converge should suitable conditions become a state of unity at the end i.e. including the individual's goals in organization's goals.

Al-Shamri (2012) defined it as an internal and external persuading process through the individual's wishes merged in the organization's wishes with the result that a state of symmetry would be created on the basis of integration of such desires.

The researcher means in the current investigation that the organizational identification is the specialist's sense and feeling with conformity with the department of youth welfare making him think about how to develop it and how to develop himself and to get succeeded for it with all his owning skills till achieving goals outlined as his personal goals.

Research method: 
The researcher used the descriptive method with the scanning technique to carry out the current investigation for the nature of the research as she had to describe what existed.

Research people and sample:

They were selected intentionally and with comprehensive inventory of specialists in departments of youth welfare, Helwan University. They comprised (94) specialists and (15) specialists were selected from the research people to conduct the pilot study and computing scientific coefficients of the two questionnaire forms in their final forms on the research sample that consisted of (79) specialists. Four forms were excluded because they were uncompleted and hence, the sample became actually (75) specialists in departments of youth welfare, Helwan University.

Tools of collecting data:

- The researcher used two questionnaire forms as a tool to collect data as follows:

a- Reviewing records and documents.

b- Reviewing scientifically specialized references in the field of the research problem and studies related to the current research subject.

c- In the light of the results concluded from this perusal, the two questionnaire forms were built as follows:

The $1^{\text {st }}$ questionnaire: participative leadership among directors of departments of youth welfare, Helwan University:

1- The researcher outlined dimensions of the questionnaire and made statements covering the questionnaire dimensions.

2- The questionnaire initial form (copy a) was presented to a group of experts (att. 1). This form included four dimensions at the rate of (45 words) (att. 2) to explore their opinions with effect from 1/8/2017 to 17/8/2017.

3- All experts agreed on the questionnaire dimensions and the researcher was satisfied by $70 \%$ or more of experts' opinions about the suitability of words of the questionnaire form (att. 4).

4- Through the experts' opinions on the suitability of the questionnaire words, words No. (7 and 10) of the $1^{\text {st }}$ dimension "participation in making decision", No. (6 and 8$)$ of the $2^{\text {nd }}$ dimension "delegating power", No. $(5,8$ and 10$)$ of the $3^{\text {rd }}$ dimension "human relationships" and finally No. $(2,7$ and 10$)$ of the $4^{\text {th }}$ dimension "efficiency of communication and availability of information" were omitted and hence, the number of words of the questionnaire became (35).

5- A pentagonal assessment balance was assigned as follows: "I strongly agree $=5$ scores", "I agree $=4$ scores", "I somewhat agree $=3$ scores", "I do not agree = 2 scores" and "I strongly do not agree $=1$ score". 
6- The exploratory study of the initial form (b) of the questionnaire (att. 4) was applied from $27 / 8 / 2017$ to $7 / 9 / 2017$ to a sample of (15) specialists from the research people but not from the research sample under investigation.

The $2^{\text {nd }}$ questionnaire: organizational identification among specialists in departments of youth welfare, Helwan University.

1- The researcher outlined the questionnaire dimensions and worded phrases covering the questionnaire dimensions.

2- The questionnaire initial form (a) was presented to a group of experts (att. 1) including 3 dimensions at the rate of ( 26 words) (att. 2) to explore their opinions with effect from 1/8/2017 to 17/8/2017.

3- All experts agreed on the questionnaire dimensions. The researcher was satisfied by $\mathbf{7 0 \%}$ or more of the experts' opinions on the suitability of words of the questionnaire form (att. 3).

4- Through the experts' opinions on the suitability of words of the questionnaire, words No. (4 and 5 ) of the $1^{\text {st }}$ dimension "belonging", No. (8) of the $2^{\text {nd }}$ dimension "symmetry" and No. (6) of $3^{\text {rd }}$ dimension "loyalty" were omitted and hence, the questionnaire became containing (22) words.

5- A pentagonal assessment balance was assigned as follows: I strongly agree $=5$ scores, $I$ agree $=4$ scores, $I$ somewhat agree $=3$ scores, $I$ do not agree $=\mathbf{2}$ scores and I do not strongly agree $=1$ score.

6- The exploratory study of the questionnaire initial form (b) (att. 4) was carried out from $27 / 8 / 2017$ to $7 / 9 / 2017$ on a sample of (15) specialists from the research people but not from the sample under investigation .

I. Computing scientific coefficients of the questionnaire form (participative leadership among directors of departments of youth welfare, Helwan University):

1- Computing coefficient of validity:

a- The validity of content (arbitrators): (att. 2 and 3)

b- The validity of internal consistency:

Table (1)

Values of correlation between each word and the score of dimension belonging to it of participative leadership among directors of departments of youth welfare, Helwan

University $(n=15)$

\begin{tabular}{c|l|l|l|l|l|l|c}
\hline No. & $\begin{array}{l}1^{\text {st }} \text { dimension } \\
\text { "participation in } \\
\text { making decision". }\end{array}$ & No. & $\begin{array}{l}2^{\text {nd }} \text { dimension, } \\
\text { delegating } \\
\text { power }\end{array}$ & No. & $\begin{array}{l}3^{\text {rd }} \\
\text { dimension, } \\
\text { human } \\
\text { relationships } \\
\cdot\end{array}$ & No. & $\begin{array}{l}4^{\text {th }} \text { dimension, } \\
\text { efficiency of } \\
\text { communication } \\
\text { and availability } \\
\text { of information }\end{array}$ \\
\hline 1 & $0.792^{*}$ & 1 & $0.696^{*}$ & 1 & $0.777^{*}$ & 1 & $0.773^{*}$ \\
\hline 2 & $0.799^{*}$ & 2 & $0.601^{*}$ & 2 & $0.900^{*}$ & 2 & $0.802^{*}$ \\
\hline 3 & $0.831^{*}$ & 3 & 0.420 & 3 & $0.820^{*}$ & 3 & $0.753^{*}$ \\
\hline 4 & $0.359^{*}$ & 4 & $0.767^{*}$ & 4 & $0.575^{*}$ & 4 & $0.713^{*}$ \\
\hline
\end{tabular}




\begin{tabular}{c|c|c|c|c|c|c|c}
\hline 5 & $0.876^{*}$ & 5 & $0.663^{*}$ & 5 & $0.788^{*}$ & 5 & $0.596^{*}$ \\
\hline 6 & $0.775^{*}$ & 6 & $0.891^{*}$ & 6 & $0.839^{*}$ & 6 & $0.765^{*}$ \\
\hline 7 & $0.702^{*}$ & 7 & $0.849^{*}$ & 7 & $0.801^{*}$ & 7 & $0.725^{*}$ \\
\hline 8 & $0.802^{*}$ & 8 & $0.691^{*}$ & 8 & $0.907^{*}$ & 8 & $0.686^{*}$ \\
\hline
\end{tabular}

*Tabulated $(r)$ value at 0.05 significance level $=(0.514)$.

Data in Table (1) illustrate that there is a significant correlation between the score of each phrase and its belonging dimension excepting (2) phrases being insignificant and those are phrase No. (4) from the $1^{\text {st }}$ dimension (participation in making decision) and phrase No. (3) from the $2^{\text {nd }}$ dimension (delegating power) and hence, the form in its $3^{\text {rd }}$ copy contains (33) phrases distributed to (4) dimensions.

Table (2)

Values of correlation between the score of each phrase and total score of questionnaire of participative leadership among directors of departments of youth welfare, Helwan University $(n=15)$

\begin{tabular}{c|c|c|c|c|c|c|c}
\hline No. & $\begin{array}{c}\text { Correlation } \\
\text { coefficient }(\boldsymbol{r})\end{array}$ & No. & $\begin{array}{c}\text { Correlation } \\
\text { coefficient }(\boldsymbol{r})\end{array}$ & No. & $\begin{array}{c}\text { Correlation } \\
\text { coefficient }(\boldsymbol{r})\end{array}$ & No. & $\begin{array}{c}\text { Correlation } \\
\text { coefficient }(\boldsymbol{r})\end{array}$ \\
\hline 1 & $0.878^{*}$ & 10 & $0.592^{*}$ & 19 & $0.602^{*}$ & 28 & $0.846^{*}$ \\
\hline 2 & $0.624^{*}$ & 11 & $0.666^{*}$ & 20 & $0.824^{*}$ & 29 & $0.566^{*}$ \\
\hline 3 & $0.813^{*}$ & 12 & $0.580^{*}$ & 21 & $0.718^{*}$ & 30 & $0.700^{*}$ \\
\hline 4 & $0.590^{*}$ & 13 & $0.613^{*}$ & 22 & $0.577^{*}$ & 31 & $0.546^{*}$ \\
\hline 5 & $0.777^{*}$ & 14 & $0.552^{*}$ & 23 & $0.877^{*}$ & 32 & $0.832^{*}$ \\
\hline 6 & $0.601^{*}$ & 15 & $0.655^{*}$ & 24 & $0.565^{*}$ & 33 & $0.578^{*}$ \\
\hline 7 & $0.564^{*}$ & 16 & $0.854^{*}$ & 25 & $0.600^{*}$ & & \\
\hline 8 & $0.583^{*}$ & 17 & $0.547^{*}$ & 26 & $0.555^{*}$ & & \\
\hline 9 & $0.579^{*}$ & 18 & $0.559^{*}$ & 27 & $0.665^{*}$ & &
\end{tabular}

Tabulated $(r)$ value at $(0.05)$ significance level $=(0.514)$.

Data in Table (2) show that there is a significant correlation between the score of each phrase and total score of the questionnaire form under investigation.

Table (3)

Values of correlation between the score of each dimension and total score of questionnaire of participative leadership among directors of departments of youth welfare $(n=15)$

\begin{tabular}{c|l|c|c}
\hline No. & \multicolumn{1}{|c|}{ Dimensions } & $\begin{array}{c}\text { Phrases } \\
\text { No. }\end{array}$ & $\begin{array}{c}\text { Correlation } \\
\text { coefficient }(\boldsymbol{r})\end{array}$ \\
\hline 1 & Participation in making decision. & 7 & $0.690^{*}$ \\
\hline 2 & Delegating power & 8 & $0.711^{*}$ \\
\hline 3 & Human relationships & 9 & $0.843^{*}$ \\
\hline 4 & $\begin{array}{l}\text { Efficiency of communication and availability of } \\
\text { information }\end{array}$ & 9 & $0.700^{*}$ \\
\hline
\end{tabular}

*Tabulated $(r)$ value at $(0.05)$ significance level $=(0.514)$.

Data in Table (3) illustrate that there is a significant correlation between the score of each dimension and total score of the questionnaire meaning that dimensions and phrases of the questionnaire form have an acceptable score of validity and they are applicable.

2- Computing the stability coefficient: 
Table (4)

Values of alpha Kronbach for half splitting to compute stability of participative leadership questionnaire among directors of departments of youth welfare, Helwan

University $(\mathbf{n}=15)$

\begin{tabular}{c|c|c}
\hline No. & Statement & $\begin{array}{c}\text { Participative } \\
\text { leadership }\end{array}$ \\
\hline 1 & Correlation coefficient between two parts & 0.8630 \\
\hline 2 & Jtman coefficient & 0.9260 \\
\hline 3 & Alpha coefficient for the $1^{\text {st }}$ part & 0.9460 \\
\hline 4 & Alpha coefficient for the $2^{\text {nd }}$ part & 0.8111 \\
\hline
\end{tabular}

Data in Table (4) indicate that the correlation coefficient between the two parts is (0.8630) and such values are acceptable for stability of the questionnaire form under investigation meaning that dimensions and phrases of the questionnaire form having an acceptable score of stability and hence, the final form is valid for application.

Therefore, the number of phrases of the questionnaire under investigation became (33) distributed as follows: phrases from (1 to 7) represent the $1^{\text {st }}$ dimension i.e. participation in making decision. Phrases from (8-15) are the $2^{\text {nd }}$ dimension i.e. delegating power. Phrases from $(16$ to 24$)$ are the $3^{\text {rd }}$ dimension i.e. human relationships. Phrases from (25 to 33 ) are for the $4^{\text {th }}$ dimension i.e. efficiency of communication and availability of information (att. 5).

A pentagonal assessment balance was assigned that is I strongly agree $=\mathbf{5}$ scores, I agree $=4$ scores, I somewhat agree $=\mathbf{3}$ scores, I do not agree $=\mathbf{2}$ scores and I do not strongly agree $=1$ score.

Consequently, the score of practicing participative leadership from (33 to 77), (78 to 121) and (122 to 165) will be low, medium and high; respectively.

II. Computing scientific coefficients of the questionnaire form (organizational identification among specialists in departments of youth welfare, Helwan University):

1- Computing validity coefficient:

a. Validity of content (arbitrator): (att. $2 \& 3$ )

b. Validity of internal consistency:

Table (5)

Values of correlation between the score of each phrase and its belonging dimension for questionnaire of organizational identification among specialists in departments of youth welfare, Helwan University $(n=15)$

\begin{tabular}{c|c|c|c|c|c}
\hline No. & $1^{\text {st }}$ dimension, belonging & No. & $\begin{array}{c}2^{\text {nd }} \text { dimension, } \\
\text { symmetry }\end{array}$ & No. & $3^{\text {rd }}$ dimension, loyalty \\
\hline 1 & 0.501 & 1 & $0.895^{*}$ & 1 & $0.822^{*}$ \\
\hline 2 & $0.911^{*}$ & 2 & $0.739^{*}$ & 2 & $0.919^{*}$ \\
\hline 3 & $0.894^{*}$ & 3 & 0.483 & 3 & 0.507 \\
\hline 4 & $0.923^{*}$ & 4 & $0.564^{*}$ & 4 & $0.957^{*}$ \\
\hline 5 & $0.797^{*}$ & 5 & $0.845^{*}$ & 5 & $0.523^{*}$ \\
\hline 6 & $0.955^{*}$ & 6 & $0.849^{*}$ & 6 & $0.867^{*}$ \\
\hline
\end{tabular}




\begin{tabular}{c|l|l|l|l|l}
\hline 7 & $0.709^{*}$ & 7 & $0.735^{*}$ & 7 & $0.742^{*}$ \\
\hline 8 & $0.646^{*}$ & \multicolumn{3}{|c}{} \\
\cline { 1 - 3 }
\end{tabular}

*Tabulated $(\mathbf{r})$ value at $(\mathbf{0 . 0 5})$ significance level $=(\mathbf{0 . 5 1 4})$.

Data in Table (5) indicate that there is a significant correlation between the score of each phrase and its belonging dimension excepting (3) phrases being insignificant and those are phrase No. (1) from $1^{\text {st }}$ dimension i.e. (belonging), phrase No. (3) from $2^{\text {nd }}$ dimension i.e. (symmetry) and phrase No. (3) from $3^{\text {rd }}$ dimension i.e. (loyalty) and hence, the third copy of the form contains (19) phrases distributed to (3) basic dimensions.

Table (6)

Values of correlation between the score of each phrase and total score of questionnaire of organizational identification among specialists in departments of youth welfare, Helwan University $(n=15)$

\begin{tabular}{|c|c|c|c|c|c|}
\hline No. & $\begin{array}{c}\text { Correlation coefficient } \\
(r)\end{array}$ & No. & $\begin{array}{c}\text { Correlation coefficient } \\
(r)\end{array}$ & No. & Correlation coefficient $(r)$ \\
\hline 1 & $0.600 *$ & 8 & $0.610^{*}$ & 15 & $0.641 *$ \\
\hline 2 & $0.621 *$ & 9 & 0.599* & 16 & $0.701 *$ \\
\hline 3 & $0.554 *$ & 10 & $0.713^{*}$ & 17 & $0.583^{*}$ \\
\hline 4 & $0.582 *$ & 11 & $0.592 *$ & 18 & $0.708 *$ \\
\hline 5 & $0.673^{*}$ & 12 & $0.714^{*}$ & 19 & $0.672 *$ \\
\hline 6 & $0.751 *$ & 13 & $0.632 *$ & & \\
\hline 7 & $0.655^{*}$ & 14 & $0.553 *$ & & \\
\hline
\end{tabular}

Data in Table (6) show that there is a significant correlation between the score of each phrase and total score of the questionnaire form under investigation.

Table (7)

Values of correlation between the score of each phrase and total score of the organizational identification questionnaire form among specialists in departments of youth welfare, Helwan University $(n=15)$

\begin{tabular}{c|c|c|c}
\hline No. & Dimensions & $\begin{array}{c}\text { Number of } \\
\text { phrases }\end{array}$ & Correlation coefficient $(\boldsymbol{r})$ \\
\hline 1 & Belonging & 7 & $0.910^{*}$ \\
\hline 2 & Symmetry & 6 & $0.852^{*}$ \\
\hline 3 & Loyalty & 6 & $0.713^{*}$ \\
\hline
\end{tabular}

*Tabulated $(r)$ value at $(0.05)$ significance level $=(0.514)$.

Data in Table (7) illustrate that there is a significant correlation between the score of each dimension and total score of the questionnaire under investigation i.e. dimensions and phrases of the questionnaire form have an acceptable score of validity and they are valid for application.

2- Computing stability coefficient: 
Table (8)

Values of alpha Kronbach for half splitting to compute the organizational identification questionnaire form stability among specialists in departments of youth welfare, Helwan University $(n=15)$

\begin{tabular}{c|c|c}
\hline No. & Statement & $\begin{array}{c}\text { Participative } \\
\text { leadership }\end{array}$ \\
\hline 1 & Correlation coefficient between two parts & 0.9150 \\
\hline 2 & Jtman coefficient & 0.9540 \\
\hline 3 & Alpha coefficient for the $1^{\text {st }}$ part & 0.9290 \\
\hline 4 & Alpha coefficient for the $2^{\text {nd }}$ part & 0.9030 \\
\hline
\end{tabular}

Data in Table (8) show that the correlation coefficient between the two parts is (0.9150) and those values are acceptable for the form stability under investigation and hence, dimensions and phrases of the questionnaire have an acceptance score of stability and the form is applicable in its final copy.

Therefore, the number of phrases of the questionnaire under investigation becomes (19) distributed as follows: Phrases from No. (1 to 7), from No. (8 to 13) and from No. (14 to 19$)$ are for the $1^{\text {st }}$ dimension, $2^{\text {nd }}$ dimension and $3^{\text {rd }}$ dimension; respectively.

A pentagonal assessment balance was assigned that is I strongly agree $\mathbf{~} 5$ scores, I agree $=4$ scores, $I$ somewhat agree $=\mathbf{3}$ scores, I do not agree $=\mathbf{2}$ scores and I do not strongly agree $=1$ score.

Therefore, the level of organizational identification from (19 to 44 scores), from (45 to 70 scores) and from ( 71 to 95 scores) becomes low, medium and high; respectively.

Basic study:

The researcher applied the two questionnaire forms viz. participative leadership among directors of departments of youth welfare, Helwan University and organizational identification among specialists in departments of youth welfare, Helwan University in their final copies (att. 5) to (75) research sample individuals of specialists in departments of youth welfare, Helwan University after assuring of the validity and stability of the two forms of the questionnaire. The procedures of application took place from 17/9/2017 to 18/10/2017.

Statistical treatments used:

1- Descriptive statistics.3

2- Pearson correlation values.

3- Alpha Kronbach values.

4- Stepwise regression analysis

Prediction equation $\quad \mathbf{Y}=\mathbf{a}+\mathbf{b}_{1} \mathbf{X}_{1}$

As:

$\mathbf{y}=$ Dependent variable.

$\mathbf{a}=$ Constant value. 
$\mathrm{B}=$ Contributor variable .

$\mathrm{X}=$ Arithmetic mean.

Presentation and discussion of results:

In the light of the answer to the research questions through theoretical framework referential researches and studies, the results were discussed and explained as follows:

Table (9)

Arithmetic mean, standard deviation and skewness coefficient of responses of the sample to dimensions of participative leadership questionnaire form under investigation $(\mathbf{n}=75)$

\begin{tabular}{c|l|c|c|c}
\hline No. & \multicolumn{1}{|c|}{ Dimensions } & $\mathrm{X}^{-}$ & SD & $\begin{array}{c}\text { Skewness } \\
\text { co. }\end{array}$ \\
\hline 1 & Participation in making decision & 26.56 & 4.09 & 0.211 \\
\hline 2 & Delegating power & 29.77 & 3.96 & 0.215 \\
\hline 3 & Human relationships & 33.58 & 5.51 & 0.604 \\
\hline 4 & $\begin{array}{l}\text { Efficiency of communication and availability of } \\
\text { information }\end{array}$ & 32.69 & 5.32 & 0.701 \\
\hline \multicolumn{1}{|c|}{ Total score } & 122.61 & 17.33 & 0.526 \\
\hline
\end{tabular}

Data in Table (9) show that values of arithmetic means of responses of the research sample to dimensions of participative leadership among directors of departments of youth welfare, Helwan University are varied as the value of skewness coefficient ranges from $( \pm 3)$ meaning normality of such data.

Noticeably, the arithmetic mean of dimension of human relationships has the highest value recording (33.58) followed by dimensions of efficiency of communication, delegating power, participation in making decision recording (32.69), (29.77) and (26.56); respectively meaning that human relationships is the most dimension being practiced among directors of departments of youth welfare, Helwan University in recognition of the sample individuals of specialists and from their point of view as it is shown that directors of departments have a higher score of practicing the most important aspect in human relationships with specialists working in their departments that positively reflected to the specialists towards achieving the work objectives.

These results indicate that the research sample of specialists recognize the important role played by human relationships as a sole dimension of participative leadership can be practiced satisfactory among directors.

The researcher thinks that the meaning of human relationships is to provide an atmosphere prevailing with mutual respect and flexibility from the director of youth welfare in dealing with not only specialists in the department but also with specialists among each other with the result that the suitable atmosphere is created in the work.

The researcher attributes that the directors are characterized by a score of practicing the dimension of human relationships due to their style in managing job teams of specialists in departments of youth welfare depending on taking care of 
human relationships through holding periodical and friendly meetings with them, considering social courtesies, developing positive attitudes among specialists, encouraging rejuvenation and creativity, achieving the principle of justice and equality in evaluation of specialists and avoiding bias of any specialist and consequently, an atmosphere prevailing with understanding is created among specialists and the targeted job goals are established.

Also Nadia Al-Dawas in her study (2016) recommended that human relationships should be supported in learning and educational environments, mechanisms had to be placed to apply participative leadership to running its affairs and to managing its work.

Dina Al-Subaie (2014) indicated that marginalization of the human nature of subordinates and not giving them the necessary attention had an effect on falling traditional and classical theories in management to achieve its wishes and aspirations to increase productivity.

Ahmed Zuhair (2017) indicated that characteristics of participative leadership was interested primarily in human relationships and their prevailing morale, sense of satisfaction and general believe in the individual's value .

The result of the current investigation agreed with those of Ahmed Zuhair (2017) and Abdel Aziz Abdel Rahman (2016) in giving human relationships the first order among dimensions of participative leadership.

Contrarily, the result of the current investigation disagreed with that of Amal Al-Fahaid (2013) in giving the dimension of human relationships the second order among participative leadership dimensions.

Also, data in Table (9) show that the total score of participative leadership is (122.61) meaning that the score of practicing such leadership is high among directors of departments of youth welfare, Helwan University as this score is located between $(122-165)$ as an indicator to the high level of practicing participative leadership.

The researcher attributed that to differentiation of directors of departments of youth welfare, Helwan University of making decision and delegating power together with specialists when requested in the department, to specialized human relationships and to efficiency of communication and availability of information in departments of youth welfare and hence reflecting to those specialists for its importance in achieving success in different activities and competitions.

Also the study of Halima Yahiya (2012) indicated that administrative processes carried out by the director together with the staff aimed at developing aspects of leadership among them, investing their capabilities and providing them with the chance for creativity and innovation.

Also the study of Abdulla Abo Aitah (2015) illustrated that participative leadership was one of the administrative techniques benefiting everyone applying it as it made use of ideas of the staff as well as taking part in making decision and hence the staff were eager to success because they were partners in it. 
Also the study of Al-Mahmadi cited from Smith (2015) showed that there were several characteristics made participative leadership be one of the leading attitudes in management as periodical meetings between the leadership and staff and their participation in making decision gaining them more mutual confidence, contributing to their motivation to make their best effort and increasing their morale and hence establishing goals of the organization.

The result of the current investigation agreed with those of Ahmed Zuhair (2017), Rania Al-Refai (2016), Ayed Ziab (2016), Sheikha Fawaz (2015) and Khalid AlMahmadi (2015) in outlining the score of practicing participative leadership through responses of the research sample individuals with high score from practicing leadership.

Whereas the result of the current investigation disagreed with this those of Abdel Aziz Al-Asker (2016), Bandar Al-Matairi (2015) and Manar Ahmed (2015) that the score of practicing participative leadership was medium.

Also the result of the current study was inconsistent with that of Amal AlFahaid (2013) that the score of practicing participative leadership was low.

Such results concluded from Table (9) answer to the $1^{\text {st }}$ question stating, "what is the score of practicing participative leadership among directors of departments of youth welfare, Helwan University from specialist's point of view?"

Table (10)

Arithmetic mean, standard deviation and skewness coefficient of responses of the sample to dimensions of organizational identification questionnaire form under investigation $(n=75)$

\begin{tabular}{c|c|c|c|c}
\hline No. & Dimensions & $\mathbf{X}^{-}$ & SD & $\begin{array}{c}\text { Skewness } \\
\text { coefficient }\end{array}$ \\
\hline 1 & Belonging & 27.21 & 4.43 & 0.304 \\
\hline 2 & Symmetry & 21.64 & 4.47 & 0.190 \\
\hline 3 & Loyalty & 24.20 & 3.21 & 0.183 \\
\hline & Total & 73.05 & 11.55 & 0.315 \\
\hline
\end{tabular}

Data in Table (10) show that values of arithmetic means of responses of the research sample to dimensions of organizational identification questionnaire form are varied among specialists in departments of youth welfare, Helwan University as the skewness coefficient ranges from $( \pm 3)$ meaning normality of data.

It is noticed from Table (10) that the arithmetic mean of dimension of belonging has the highest value recording (27.21) followed by dimensions of loyalty and symmetry recording (24.20) and (21.64); respectively indicating that belonging is the most dimension of organizational identification in recognition of responses of the research sample of specialists as a high level among them in departments of youth welfare, Helwan University as this dimension means the specialist's sense of the actual, the 
existing or the legal association linking him through his work and specialization with department of youth welfare.

The researcher attributed that the research sample of specialists in departments of youth welfare, Helwan University had a continuous sense of belonging to their work, doing their best to achieve the objectives of youth welfare, developing their skills by working to reach the distinguished performance and considering tasks of the position to get advanced ranks in student activities.

Khalid Saleh (2015) indicated that the desire to belong to the establishment, to work within its staff would make the individual have the sense of being a part of it, believe in its goals, look forward to executing them and eager to set up good relationships with his colleagues.

The study of Turki Al-Otaibi (2016) showed that belonging appeared through the expression between the pride of the organization and self-conviction of its goals and values.

The result of the current investigation agreed with that of Turki Al-Otaibi (2016) that belonging got the first order among dimensions of organizational identification.

Such result differentiated from that of Salman and Saleh (2015) that belonging had a medium score.

Also data in Table (10) illustrate that the total score of organizational identification is (73.05) meaning that the level of such organizational identification is high among specialists in departments of youth welfare, Helwan University as this score is located between (71 to 95) as an indicator of the high level of organizational identification.

The researcher related that to the research sample of specialists who had a sense of correspondence to the department of youth welfare making them think about how to develop it and themselves, to achieve success for it with all skills they own till establishing goals placed as their personal goals in addition to the specialist's sense of actual association linked him with the department of youth welfare through his attention to perform his work requirements and symmetryof the work characteristics to his own characteristics leading to emotional bonding of the specialist with his work and to drive him to work hard and to carry out plans being assigned successfully and hence reflecting to performance of specialists in an attempt to tackle the problems of lacking their number by doing different functional tasks in committees of youth welfare as possible to execute plans of activities and competitions being placed.

Ahmed Al-Shamri (2012) indicated that the individual characterized by identification with his establishment would be ready to accept and to be in harmony with objectives in addition to group decisions, to be more reactive and communication with colleagues as well as being prepared to work on carrying out decisions and goals.

Also the study of Taha Al-Shawawrah (2016) indicated that the importance of organizational identification poured at the end into the organization's interest to 
achieve its goals efficiently and effectively and in the interest of the individual himself by developing the spirit of belonging and loyalty within the individual and hence developing creativity, innovation and cooperation.

The result of the current study agreed with that of Turki Al-Otaibi (2016), AlGhazali \& Al-Khuzaei (2016), Demir \& Kamile (2015) and Aya Al-Amoshi (2014) in defining the level of organizational identification through responses of the research sample individuals with high level of organizational identification.

Whereas such result differentiated with those of Taha Al-Shawawrah (2016), Salman \& Saleh (2015), Basara \& Syory (2015), Sirin \& Yeliz (2015) and Khlod AlZughbi (2013) that the level of organizational identification recorded a medium score.

Hence, these results concluded from Table (10) answer the $2^{\text {nd }}$ question stating, "what is the level of organizational identification among specialists in departments of youth welfare, Helwan University?"

\section{Table (11)}

Values of correlation among responses of the sample to dimensions of the two questionnaire forms (participative leadership and organizational identification) under investigation $(n=75)$

\begin{tabular}{|c|c|c|c|c|c|}
\hline $\begin{array}{l}\text { Organizational identification } \\
\text { Participative leadership } \\
\end{array}$ & Description & $\begin{array}{c}1^{\text {st }} \\
\text { dimension } \\
\text { Belonging }\end{array}$ & $\begin{array}{c}2^{\text {nd }} \\
\text { dimension } \\
\text { symmetry }\end{array}$ & $\begin{array}{c}3^{\text {rd }} \\
\text { dimension } \\
\text { loyalty }\end{array}$ & Total \\
\hline \multirow{2}{*}{$\begin{array}{l}1^{\text {st }} \text { dimension: participation in making } \\
\text { decision. }\end{array}$} & $r$ & $0.385^{*}$ & $0.511^{*}$ & $0.470 *$ & $0.476 *$ \\
\hline & Sig. & 0.001 & 0.000 & 0.000 & 0.000 \\
\hline \multirow{2}{*}{ 2dimension:Delegating power } & $r$ & $0.465^{*}$ & $0.532 *$ & $0.451^{*}$ & $0.510 *$ \\
\hline & Sig. & 0.000 & 0.000 & 0.000 & 0.000 \\
\hline \multirow{2}{*}{$3^{\text {rd }}$ dimension: Human relationships } & $r$ & $0.313^{*}$ & $0.346^{*}$ & $0.318^{*}$ & $0.342 *$ \\
\hline & Sig. & 0.000 & 0.000 & 0.000 & 0.000 \\
\hline \multirow{4}{*}{$\begin{array}{l}4^{\text {th }} \text { dimension: Efficiency of } \\
\text { communication and availability of } \\
\text { information }\end{array}$} & $r$ & $0.427^{*}$ & $0.457^{*}$ & $0.461^{*}$ & $0.469 *$ \\
\hline & Sig. & 0.000 & 0.000 & 0.000 & 0.000 \\
\hline & $r$ & $0.428 *$ & $0.493^{*}$ & $0.457^{*}$ & $0.482 *$ \\
\hline & Sig. & 0.000 & 0.000 & 0.000 & 0.000 \\
\hline
\end{tabular}

*Significance level $<0.05$

Data in Table (11) show that there is a significantly direct correlation between dimensions of participative leadership questionnaire form and all dimensions and total score of organizational identification questionnaire form.

Computing the linear regression equation: 
Table (11)

Ratio of contribution of dimensions of participative leadership in achieving the total score of organizational identification

\begin{tabular}{c|c|c|c|c|c}
\hline Step & Constant & Standard & \multirow{2}{*}{$F$} & $\begin{array}{c}\text { Contributed } \\
\text { dimensions }\end{array}$ & \multirow{2}{*}{$\begin{array}{c}\text { of } \\
\text { error }\end{array}$} \\
\cline { 3 - 5 } & value & $\begin{array}{c}2^{\text {nd }} \text { dimension } \\
\text { (delegating } \\
\text { power) }\end{array}$ & \\
\hline 1 & 28.87 & 8.80 & 25.62 & 1.48 & $51.00 \%$ \\
\hline
\end{tabular}

Data in Table (12) illustrate that the ratio of contribution of the $2^{\text {nd }}$ dimension (delegating power) in participative leadership is $(\mathbf{5 1 . 0 0 \%})$ to achieve the total score of organizational identification and hence, it is possible to predict the following equation:

$$
\mathbf{Y}=\mathbf{a}+\mathbf{b}_{1} \mathbf{x}_{1}
$$

Organizational identification $=28.87+(1.48 \times$ Delegating power $)$

Noticeably data in Tables $(11 \& 12)$ show that in the light of responses of the research sample, there is a significant direct correlation between the score of dimensions of participative leadership and the level of dimensions of organizational identification and their total score. The ratio of contribution of the $2^{\text {nd }}$ dimension (delegating power) is originated only from dimensions of participative leadership showing the ratio of contribution of dimensions of participative leadership in outlining the level of organizational identification among specialists in departments of youth welfare, Helwan University.

That means as the score of practicing participative leadership is increased among directors of departments of youth welfare the level of organizational identification gets higher among specialists in departments of youth welfare, Helwan University.

The researcher attributed that to the existence of leaderships practicing participative leadership represented by directors of departments of youth welfare giving attention to specialists, associating them in making decision, practicing delegating power, contributing to forming human relationships and working on efficiency of communication and availability of information transparently. Also there are specialists being organizationally symmetric with departments of youth welfare, belonging to them, setting up strong relationships with them, considering their goals as personal goals for them and seeking to carry out different activities and hence contributing to the success of departments of youth welfare, Helwan University and driving the workflow wheel towards achieving goals.

Ahmed Zuhair (2017) indicated that participative leadership was one of the new modern leadership types where the leader associated with his subordinates in the process of making the administrative decision. He discussed them respecting their 
personalities and investing their creative capabilities for achieving the establishment's goals.

Zainab Aboud (2016) clarified that organizational symmetry made the process of making decision consider the organization's goals, increase the staff performance, give the employee conviction of action having preparedness for staying in the organization, do the best to improve and to develop the performance, contribute to improve the position of the organization in the society and upgrade its competitive capacity.

The result of the current study agreed with those of Rania Al-Refai (2016), Ayed Ziab (2016) and Manar Mansour (2015) through the relationship of participative leadership with different variables, it had a significantly direct correlation.

Also the result of the current study was in conformity with those of Salem AlShawawrah (2016), Al-Ghazali \& Al-Khuzaei (2016), Aya Al-Amoshi (2014) and Khloud Al-Zughbi (2013) through the relationship of organizational identification with different variables it had a significantly direct correlation.

Such results concluded from Tables $(11 \& 12)$ answer the $3^{\text {rd }}$ and $4^{\text {th }}$ questions stating, "is there a significant correlation between participative leadership and organizational identification among specialists in departments of youth welfare, Helwan University?" and "what is the ratio of contribution of dimensions of participative leadership to outline the level of organization identification among specialists in departments of youth welfare, Helwan University?"

Results:

The researcher concluded the following results:

1- The score of practicing participative leadership among directors of departments of youth welfare, Helwan University is high.

2- The level of organizational identification among specialists in departments of youth welfare, Helwan University has a high score.

3- There is a significantly direct correlation between participative leadership and organizational identification among specialists in departments of youth welfare, Helwan University.

4- Dimension of delegating power gets the highest ratio of contribution of participative leadership to outline the level of organizational identification among specialists in departments of youth welfare, Helwan University according to opinions of the research sample.

Recommendations:

In the limit of the research sample, its procedures and on the basis of the results concluded, the researcher recommended the following:

1- Values of participative leadership and organizational identification should be supported as two important elements for establishing goals of departments of youth welfare. 
2- The culture of organizational identification should be instilled among specialists in departments of youth welfare to assure of continuous work success.

3- Making benefits from teaching board members in the university and through specialization of management and psychology to set up training courses and workshops for specialists and directors in departments of youth welfare on the importance of practicing participative leadership and organizational identification.

4- Providing job grades in the university to appoint new specialists in departments of youth welfare for lacking the number of such specialists in the university and to accomplish work.

References

I. Arabic references:

1- Ahmed Zuhair Zachariah (2017): A Suggested imagination to develop skills of participative leadership among directors of secondary schools in Gaza Governorates. Master of educational administration, Faculty of Education, Islamic University, Gaza.

2- Ahmed Matter Al-Shamri (2012): The score of practicing leading roles among deans of faculties in Kuwait and its relationship with organizational identification among members of the teaching board from their point of view, M. Sc. Unpublished Thesis, Faculty of Educational Sciences, Middle East University, Amman, Jordan.

3- Amal Al-Fahaid (2013): The score of using participative leadership type among directresses of secondary schools in the city of Hail, M. Sc. Thesis, King Abdel Aziz University, Jeddah.

4- Aya Khalid Mohammed Al-Amoshi (2014): The score of practicing skills of administrative communication by deans of colleges and its relationship with the level of organizational identification among members of teaching board in the official Jordanian universities, M. Sc. Thesis, College of Educational Administration, Hashemite University, Zarqa, Jordan.

5- Bandar Al-Basis Al-Matairi (2015): The score of practicing participative leadership by directors of the secondary stage schools in Hafr Al-Batin Governorate and its relationship with organizational loyalty among teachers. M. Sc. Thesis, Umm Al-Qura University, Makka Al-Mukarrama.

6- Turki Bin Kadimis Al-Otaibi (2016): Organizational identification among members of teaching board, Al-Taif University, Journal of Educational and Psychological Sciences, Al-Quassaim University, Vol. (9), Ed. (3).

7- Halima Yahiya Laheq (2012): The score of practicing participative leadership by directresses of governmental secondary schools in Asir province, unpublished M. Sc. Thesis, King Khalid University, Abha, K. S. A.

8- Khalid Mohammed Al- Mahmadi (2015): The score of practicing participative leadership by directors of Education Offices in Makka Al-Mukarrama and its relationship with morale from supervisors' point of view, unpublished 
M. Sc. Thesis, Faculty of Education, Dept. of Educational and Planning Administration, Umm Al-Qura University, Makka Al-Mukarrama.

9- Khudair Kazem Mahmoud and Rowan Munir Al-Sheikh (2010): Quality Management in Distinguished Organizations. Safaa Publishing and Distribution House, Amman, Jordan, pp. 147.

10- Khloud Fawaz Al-Zughbi (2013): The score of practicing dimensions of transformational leadership by directors of private schools in Amman the Capital and its relationship with organizational identification from teachers' point of view, unpublished M. Sc. Thesis, College of Educational Sciences, Middle East University.

11-Dina Mohammed Al-Subaie (2014): Administrative empowerment among directors of secondary schools in Al-Ihsaa Governorate- reality and ways of Development, M. Sc. Thesis, King Faisal University, Al-Ihsaa, K. S. A. pp. 74.

12- Rania Mohammed Al-Refai (2016): The score of practicing participative leadership by directresses of secondary schools in the city of Jeddah and its relationship with professional development from teachers' point of view . Deanship of Graduate Studies and Scientific Research, Journal of Palestine University for Researches and Studies, Palestine University, Vol. (6).

13-Zainab Abdel Razik Aboud (2016): Effect of personal values on crystallizing organizational identification. Journal of College of Management and Economy for Economic Studies, Babylon University, Iraq, 212, (18).

14-Sheikha Mohammed Fawaz (2015): Practicing participative leadership by directresses of education offices in the city of Riyadh and its relationship with job satisfaction among educational supervisors. Unpublished M. Sc. Thesis, Faculty of Social Sciences, Department of Management and Planning, Imam Mohammed Bin Saud Islamic University.

15- Taha Salem Al-Shawawrah (2016): Effect of organizational identification on work motivation among teachers of Jordanian Ministry of Education in Directorate of Education, Kark, Journal of Islamic University for Economic and Administrative Studies, The Hashemite Kingdom of Jordan, Vol. (24), pp. 124.

16- Ayed Mustafa Ziab (2016): The score of practicing participative leadership by directors of secondary schools in Gaza Governorate and its relationship with self-effectiveness of their teachers. M. Sc. Thesis, Faculty of Education, Islamic University, Gaza.

17- Abdel Rahman Azmulla Al-Ghamdi (2014): A suggested strategy to develop management of schools of system of secondary courses in the light of introduction of participative leadership, unpublished Ph. D. Thesis, King Saud University, Riyadh. 
18- Abdel Aziz Bin Abdel Rahman Al-Askar (2016): The score of practicing participative leadership by directors general in directorates general in Ministry of Education, Faculty of Girls, Ain Shams University, Journal of Scientific Researches in Education, Vol. (3), Issue No. (17).

19- Abdulla Afif Abu Aitah (2013): Obstacles of using participative style in school administration in Gaza governorates and ways to treat them, unpublished M. Sc. Thesis, Islamic University, Gaza, pp. 32.

20-Abdulla Fahd Al-Qurashi (2013): Practicing participative leadership among directors of education offices and their contribution to solving problems of school administration in the secondary stage in the city of Al-Taif, unpublished M. Sc. Thesis, Umm Al-Qura University, Makka AlMukarrama, pp. 13.

21- Fadel Hamad Salman and Khalid Mahdi Salah (2015): Effect of constructive conflict in organizational identification, applied research in Ministry of Planning, Iraq, Journal of Economic and Administrative Sciences, Iraq, Vol. (21), Issue No. (82).

22- Fadel Radi Al-Ghazali and Sadam Kazem Al-Khuzaei (2016): Role of spiritual leadership in supporting organizational identification, Journal of Qadisiyah for Administrative Sciences, Vol. (18), Issue No. (4).

23- Latifa Yakoub Abu Al-Khair (2013): The score of practicing participative leadership by heads of academic departments in Jordanian Private Universities in Amman and its relationship with the ability to solve problems. Middle East University, Amman, Jordan, pp. 18.

24- Mohammed Sabri Hafez, Al-Hassan Bin Mohammed Al-Moghaidi and AlSayed Mahmoud Al-Behairi (2013): Leadership in Educational Establishments. The World Books for Publication and Distribution, Cairo, pp. 15.

25- Manar Mansour Ahmed (2015): The score of practicing participative leadership by heads of sections in Al-Taif University and its relationship with organizational loyalty from point of view of teaching members. Journal of Educational Sciences, Vol. (1), Issue No. (4).

26- Nadia Saleh Al-Dawas (2016): The reality of practicing participative leadership among directresses of directorates general of Ministry of Education. M. Sc. Thesis, Imam Mohammed Bin Saud Islamic University, Al-Riyadh.

II. Foreign references:

27- Basar, Ufuk; Syory, Unsal. (2015). Effects of teachers' organizational identification, educational sciences: theory \& practice, 15(1), 45-59. 
28- Demir, Kamile. (2015). Teachers' organizational citizenship behaviors and organizational identification in public and private preschools, procediasocial and behavioral sciences, ( 174 ), $1176-1182$. 29- Sirin, Yeliz. (2016). Organizational Justice, organizational trust and organizational identification, International Journal of Business and Social science, 7 (2), 126-133. 